\title{
Modelos fundamentais de moeda
}

Luis Araújo*

RESUMO - Este artigo oferece uma breve discussão dos chamados modelos fundamentais de moeda, onde a característica principal é a presença de fricções no processo de troca e o tratamento da moeda como um fenômeno de equilíbrio. Esta característica separa estes modelos de abordagens onde a moeda tem valor porque existe uma restrição tecnológica estabelecendo que um subconjunto de trocas tem que ser mediado pelo uso de moeda, e modelos onde a moeda tem valor porque entra diretamente na função utilidade dos agentes.

Palavras-chave: Fricções. Equilíbrio. Modelos de busca. Barganha.

O objetivo deste artigo é fazer uma breve discussão dos desenvolvimentos relativamente recentes em teoria monetária, cuja característica principal é o tratamento da moeda como um fenômeno de equilíbrio. Esta característica separa estes desenvolvimentos de abordagens mais aplicadas, tais como modelos onde a moeda tem valor porque existe uma restrição tecnológica estabelecendo que um subconjunto de trocas tem que ser mediado pelo uso de moeda (cash in advance); e modelos onde a moeda tem valor porque entra diretamente na função utilidade dos agentes.

O elemento central que leva à existência de um equílibrio onde a moeda tem valor é a presença de fricções no processo de troca. Claramente, este elemento não é novo, e remonta pelo menos a Menger (1892). No entanto, o esforço no sentido de um entendimento mais preciso de quais fricções são essenciais para se explicar a necessidade de moeda é mais recente. Este esforço começa com Ostroy (1973) no contexto de modelos de equilíbrio geral, e com Wallace (1978) no contexto de modelos de gerações superpostas ${ }^{1}$. No entanto, é no contexto de modelos de search que se deram os principais avanços, sendo contribuições seminais Diamond (1984), Kiyotaki e Wright (1989), e Aiyagari e Wallace (1991). Na análise que segue, eu me deterei nos modelos de search.

De um modo geral, os modelos de search consideram economias com um grande número de agentes que vivem infinitamente, e se encontram em cada período de forma relativamente decentralizada. Em particular, se assume que os agentes se encontram em pares, e atenção particular é dada ao processo de troca em um encontro entre um comprador e um vendedor. As principais fricções no ambiente são a ausência de uma tecnologia que permita a * Doutor em Economia pela Universidade da Pensilvânia. É professor associado do Departamento de Economia da Universidade Estadual de Michigan. Endereço eletrônico: araujolu@msu.edu.

1 Ver também Clower (1965), Alchian (1977) e Townsend (1980). 
observação e o monitoramento do comportamento dos agentes (record-keeping technology) e a ausência de uma tecnologia que garanta o cumprimento de contratos entre os agentes (commitment technology). Estas duas fricções fazem com que a moeda se torne essencial como mecanismo de troca, no sentido em que a moeda permite aos agentes atingirem alocações desejáveis que não seriam possíveis caso ela não tivesse valor.

Os modelos de search passaram por mudanças e aprimoramentos ao longo do tempo, mudanças estas que se refletiram sobretudo na caracterização do processo de troca entre os agentes. A primeira geração de modelos (Kiyotaki e Wright, 1993) considera um processo de troca trivial, envolvendo a troca de uma unidade de moeda por uma unidade de produto. Esta trivialidade não é imposta aos agentes, mas é obtida como parte de um equilíbrio através de hipóteses restritivas sobre a divisibilidade dos produtos e a divisibilidade da moeda. A segunda geração de modelos (Trejos e Wright, 1995, Shi, 1995) considera um processo de troca que envolve uma barganha entre o vendedor e o comprador. Nestes modelos, são relaxadas hipóteses restritivas sobre a divisibilidade dos produtos, mas hipóteses restritivas sobre a divisibilidade da moeda são mantidas. A principal vantagem desta flexibilização é que ela permite a emergência de preços endógenos e, portanto, a separação entre a margem extensiva (número de encontros entre compradores e vendedores) e a margem intensiva (quantidade produzida em cada encontro) do processo de troca.

Tanto os modelos da primeira geração quanto os modelos da segunda geração exibem equilíbrios onde os agentes escolhem mediar o processo de troca com o uso da moeda. Deste modo, uma série de questões interessantes pode ser analisada. Para citar um exemplo, considere o problema da concorrência entre moedas emitidas por diferentes instituições, um tópico certamente de interesse em uma economia globalizada onde várias moedas distintas circulam, e também de interesse em economias que passam por processos onde uma moeda local é substituída por uma moeda estrangeira (“dolarização") ${ }^{2}$. Claramente, este problema não pode ser adequadamente analisado em um modelo onde se impõe o uso de determinada moeda com alguma restrição tecnológica, ou se atribui valor a uma determinada moeda porque ela gera utilidade direta para os agentes. É necessário que se ofereça aos agentes a opção de escolher entre moedas diferentes, algo que está no cerne dos modelos de search.

No entanto, como tanto os modelos da primeira geração quanto os modelos da segunda geração assumem que a moeda é indivisível, isto os torna pouco atrativos para se estudar problemas tradicionais de política monetária como, por exemplo, o efeito de mudanças na taxa

2 Exemplos de trabalhos que investigam o processo de circulação de várias moedas são Matsuyama, Kiyotaki e Matsui (1993) e Craig, Camera e Waller (2004). 
de crescimento da quantidade de moeda sobre o bem-estar. O problema é que a introdução de uma moeda completamente divisível em um ambiente onde o processo de trocas é decentralizado apresenta dificuldades de ordem técnica que são difíceis de serem superadas. Estas dificuldades estão associadas ao fato de que a distribuição de moeda se torna endógena e não estacionária. É no sentido de superar estas dificuldades e de estabelecer uma ponte entre modelos fundamentais de moeda e a análise de políticas governamentais que se desenvolveu uma terceira geração de modelos de search. Nestes modelos, hipóteses adicionais são introduzidas, que mantêm a endogeneidade mas que eliminam a não estacionariedade da distribuição de moeda. Os trabalhos centrais são Shi (1997) e Lagos e Wright (2005). Nestes modelos, não existem hipóteses restritivas quanto à divisibilidade da moeda ou à divisibilidade dos produtos. $\mathrm{Na}$ análise que segue eu me deterei no modelo desenvolvido por Lagos e Wright (2005), dada a flexiblidade que este tem demonstrado no sentido de incoporar diversos modelos tradicionais em macroeconomia, tais como o modelo de crescimento de Solow (por exemplo, Aruoba, Waller e Wright, 2009) e modelos de precificação de ativos (por exemplo, Lagos e Rocheteau, 2009).

Lagos e Wright (2005) consideram uma economia onde os agentes intercalam encontros em um mercado decentralizado, onde produtos heterogêneos são transacionados, com encontros em um mercado centralizado, onde um produto homogêneo é transacionado. $\mathrm{O}$ mercado decentralizado funciona essencialmente da mesma forma que os modelos da segunda geração, com os termos de troca sendo definidos através de barganha. O mercado centralizado, em contraste, é um mercado walrasiano, onde os agentes tomam os preços como dados, maximizam a utilidade sujeitos a uma restrição orçamentária, e onde o equilíbrio é dado pela igualdade entre a oferta e a demanda. Uma hipótese importante é que a desutilidade de produção no mercado centralizado é linear. Esta hipótese faz com que a quantidade de moeda demandada pelo agente no mercado centralizado não dependa da quantidade de moeda que este agente tem em estoque. Combinada ao fato de que os agentes são ex-ante homogêneos, o resultado é que a distribuição de moeda em equilíbrio é degenerada, o que facilita bastante na definição dos termos de troca no mercado decentralizado.

A demanda por moeda em equilíbrio no modelo de Lagos e Wright (2005) é dada pela equação $\Phi_{s}=\beta\left\{\alpha \sigma u^{\prime}\left[q_{s+1}\left(M_{s+1}\right)\right] q_{s+1}^{\prime}\left(M_{s+1}\right)+(1-\alpha \sigma) \Phi_{s+1}\right\}$. A intuição desta equação é a seguinte: o agente tem um custo $\Phi_{s}$ quando ele demanda uma unidade adicional de moeda no período $s$ no mercado centralizado, onde $\Phi_{s}$ é o preço de uma unidade de moeda em termos do produto vendido no mercado centralizado. Esta unidade adicional é utilizada no próximo período, e portanto os benefícios sofrem um desconto $\beta$. Existe uma probabilidade $\alpha \sigma$ de que o agente encontre um outro agente no mercado decentralizado que produz o produto que ele 
gosta. Neste caso, a unidade adicional de moeda permite adquirir uma quantidade de produto $q_{s+1}^{\prime}\left(M_{s+1}\right)$, com o benefício em termos de utilidade sendo $u^{\prime}\left[q_{s+1}\left(M_{s+1}\right)\right]$. Finalmente, existe uma probabilidade 1 - $\alpha \sigma$ de que o agente não tenha a oportunidade de utilizar a moeda no mercado decentralizado. Neste caso, a moeda é utilizada no mercado centralizado, com um benefício igual a $\Phi_{s+1}$, que corresponde à quantidade do produto vendido no mercado centralizado que pode ser comprada com uma unidade de moeda. Em um steady-state onde a taxa de crescimento na quantidade de moeda é dada por $\tau$ e o valor real da moeda é constante, a demanda por moeda em equilíbrio pode ser reescrita como:

$$
\frac{u^{\prime}(q)}{z^{\prime}(q)}=1+\frac{1+\tau-\beta}{\beta \alpha \sigma}
$$

Nesta equação, ₹(q) é determinada pelo processo de barganha entre um comprador e um vendedor no mercado decentralizado, e é dada por:

$$
z(q)=\frac{\theta u^{\prime}(q)}{\theta u^{\prime}(q)+(1-\theta) c^{\prime}(q)} c(q)+\frac{(1-\theta) c^{\prime}(q)}{\theta u^{\prime}(q)+(1-\theta) c^{\prime}(q)} u(q)
$$

O parâmetro central nesta segunda expressão é $\theta$, que reflete o poder de barganha do comprador. Observando a expressão acima, dois resultados se destacam. O primeiro corresponde à regra ótima de política monetária. Consistente com modelos não fundamentais de moeda (cash in advance, moeda na função utilidade), a taxa ótima de crescimento de moeda é dada pela regra de Friedman, que recomenda uma taxa nominal de juros igual a zero. No ambiente de Lagos e Wright (2005), como não existem outros ativos além de moeda, esta regra é equivalente a uma taxa negativa de crescimento da moeda dada por $\tau=\beta-1$. O segundo resultado é que a regra de Friedman só implementa a quantidade ótima de produto no mercado decentralizado, ou seja, uma quantidade $q^{*}$ tal que $u^{\prime}\left(q^{*}\right)=c^{\prime}\left(q^{*}\right)$, quando todo o poder de barganha em uma transação no mercado decentralizado está nas mãos do comprador $(\theta=1)$. Este resultado não aparece em modelos não fundamentais porque tais modelos somente consideram mercados competitivos, onde o preço é dado e não existe a possibilidade de barganha entre os agentes. A intuição deste resultado pode ser obtida através de uma analogia com o problema de hold-up na literatura de organização industrial. Um agente que demanda uma unidade de moeda no mercado centralizado faz um investimento igual a $\Phi_{s}$, dado que ele poderia ter gasto esta unidade comprando bens no mercado centralizado. Quando este agente utiliza a moeda no mercado decentralizado, ele obtém todo o retorno deste investimento somente quando $\theta=1$. Portanto, quando $\theta<1$, o agente tem menos incentivos para investir em moeda no mercado centralizado, 
o que reduz a demanda por moeda e portanto reduz $q$. Um efeito direto do fato de que a regra de Friedman não implica a quantidade eficiente de produto é que a perda em termos de bem-estar associada a um aumento na taxa de crescimento da moeda é substancial. Isto pode ser visto no gráfico abaixo, que é uma reprodução do gráfico de Lagos e Wright (2005), página 475.

GRÁFICO 1 - CUSTO DE BEM-ESTAR DE UMA INFLAÇÃO MODERADA

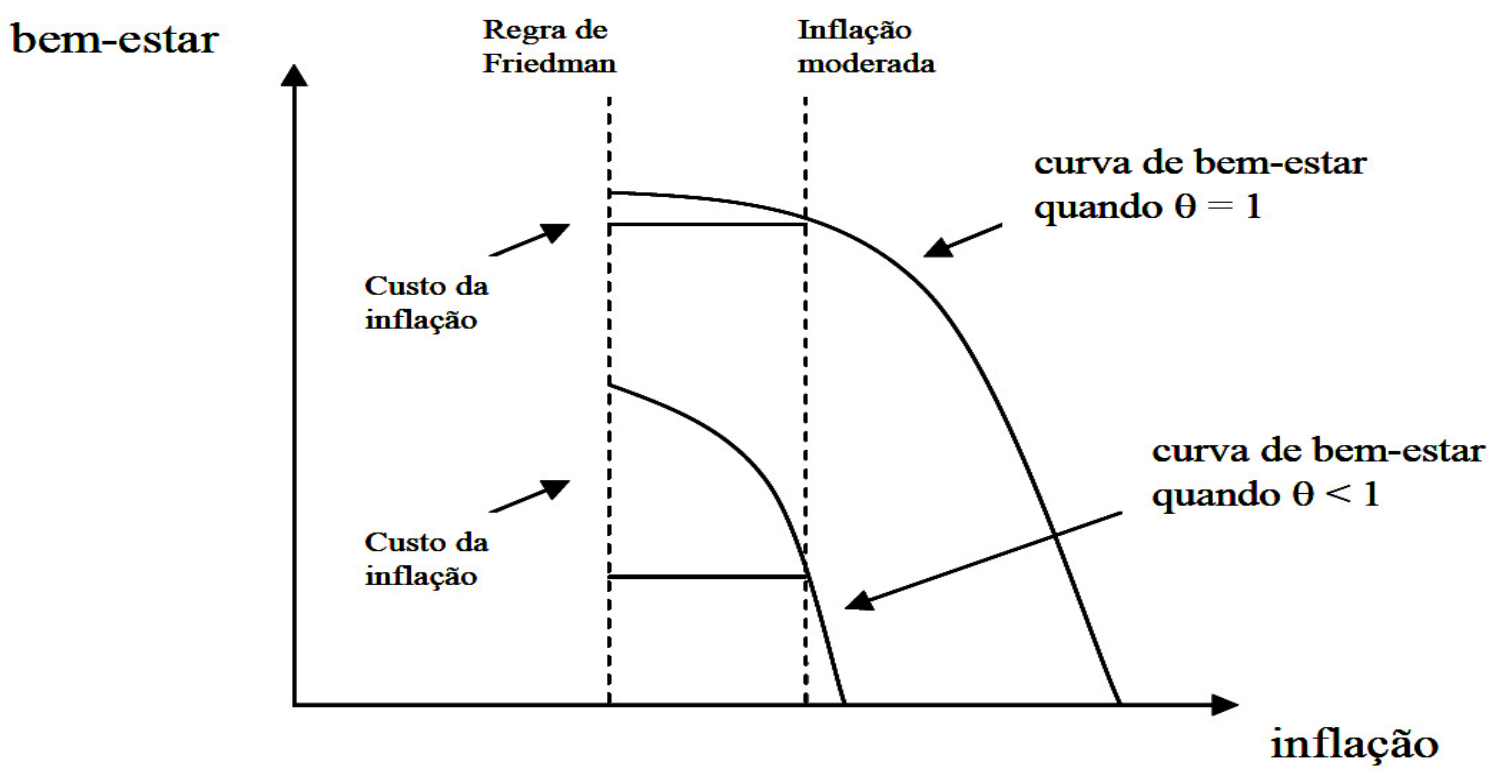

O objetivo deste breve artigo foi fazer uma discussão de desenvolvimentos relativamente recentes na teoria monetária, com um foco em modelos onde a moeda é um fenômeno de equilíbrio.

\section{REFERÊNCIAS}

ALCHIAN, A. Why money? Journal of Money, Credit, and Banking, v. 9, p. 133-140, 1977.

AIYAGARI, R.; WALLACE, N. Existence of steady-states with positive consumption in the Kiyotaki-Wright model. Review of Economic Studies, v. 58, p. 901-916, 1991.

ARUOBA, B.; WALLER, C.; WRIGHT, R. Money and capital: a quantitative analysis. Federal Reserve Bank of ST. LOUIS Working Paper, 2009.

Camera, Gabriele, Craig, e Chris Waller. Currency competition in a fundamental model of money. Journal of International Economics v. 64, p. 521- 544, 2004.

CLOWER, R. A reconsideration of the microfoundations of monetary economics. Western Economic Journal, v. 6, p. 1-8, 1965.

DIAMOND, P. Money in search equilibrium. Econometrica, v. 52, p. 1-20, 1984.

KIYOTAKI, N.; WRIGHT, R. On money as a medium of exchange. Journal of Political Economy, v. 97, p. 927-954, 1989.

KIYOTAKI, N.; WRIGHT, R. A search-theoretic approach to monetary economics. Ameri- 
can Economic Review, v. 83, p. 63-77, 1993.

LAGOS, R.; ROCHETEAU, G. Liquidity in asset markets with search frictions. Econometrica, v. 77, p. 403-426, 2009.

LAGOS, R.; WRIGHT, R. A unified framework for monetary theory and policy analysis. Journal of Political Economy, v. 113, n. 3, p. 463-484, 2005.

MATSUYAMA, K.; KIYOTAKI, N.; MATSUI, A. Toward a theory of international currency. Review of Economic Studies, v. 60, p. 283-307, 1993.

MENGER, K. On the origin of money. Economic Journal, v. 2, p. 239-255, 1892.

OSTROY, J. The informational efficiency of monetary exchange. American Economic Review, v. 63, p. 597-610, 1973.

SHI, S. Money and prices: a model of search and bargaining. Journal of Economic Theory, v. 67, p. 467-496, 1995.

SHI, S. A Divisible search model of Fiat money. Econometrica, v. 65, p. 75-102, 1997.

TOWNSEND, R. Models of money with spatially separated agents. In: KAREKEN, E. J. H.; WALLACE, N. (Ed.). Models of monetary economics. Minneapolis: Federal Reserve Bank of Minneapolis, 1980.

TREJOS, A.; WRIGHT, R. Search, bargaining, money, and prices. Journal of Political Economy, v. 103, n.1, p. 118-141, 1995.

WALLACE, N. The overlapping generations model of Fiat money. Federal Reserve Bank of Minneapolis Staff Report, n. 37, 1978. 